\title{
Back-Calculation of Fish Size in Diet Analysis of Piscivorous Predators: A New Index for the Alien Silurus glanis
}

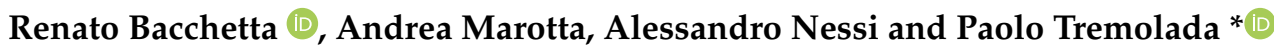 \\ Department of Environmental Science and Policy, Università degli Studi di Milano, 26, via G. Celoria, \\ I-20133 Milan, Italy; renato.bacchetta@unimi.it (R.B.); marotta.andrea92@gmail.com (A.M.); \\ alessandro.nessi93@gmail.com (A.N.) \\ * Correspondence: paolo.tremolada@unimi.it; Tel.: +39-334-7197297
}

check for updates

Citation: Bacchetta, R.; Marotta, A.; Nessi, A.; Tremolada, P.

Back-Calculation of Fish Size in Diet Analysis of Piscivorous Predators: A New Index for the Alien Silurus glanis. Sustainability 2021, 13, 4322. https:// doi.org/10.3390/su13084322

Academic Editor: Daniela Lupi

Received: 5 March 2021

Accepted: 9 April 2021

Published: 13 April 2021

Publisher's Note: MDPI stays neutral with regard to jurisdictional claims in published maps and institutional affiliations.

Copyright: (c) 2021 by the authors. Licensee MDPI, Basel, Switzerland. This article is an open access article distributed under the terms and conditions of the Creative Commons Attribution (CC BY) license (https:// creativecommons.org/licenses/by/ $4.0 /)$.

\begin{abstract}
The wels catfish Silurus glanis has been constantly spreading in many European basins, outside its native range. Being a voracious predator, it is considered to have a severe impact on local fish communities. In the Ticino River (Northern Italy), bones of S. glanis were found in feces from the top predator Lutra lutra. To estimate the control capability of L. lutra for this species and to back-calculate $S$. glanis' size from its bone remains, whole skeletons from 27 differently sized $S$. glanis specimens were analyzed. A double pharyngeal element and all caudal vertebrae emerged as significant items for species identification. The mean length of the pharyngeal element was directly related to fish mass, while for vertebrae, a K-index was proposed to identify the position of each vertebra along the spine and, from this, to calculate the original fish mass. This methodology allowed us to establish that the length of the preyed S. glanis was $85-435 \mathrm{~mm}$, and the ages were between $0+$ and $2+$ years. The proposed methodology opens new perspectives for more detailed studies on the efficiency of predation by piscivorous species on allochthonous ones.
\end{abstract}

Keywords: invasive species; Lutra lutra; diet analysis; bone remains; fish mass quantification; spraint analysis

\section{Introduction}

Native to wide areas of Eurasia, including the waters of the North, Baltic, Black, Caspian, Aral, and Aegean Sea drainages, the wels catfish Silurus glanis is the largest European freshwater fish [1]. The large size and frequent captures have increased its popularity among fishermen, leading to irregular introductions in many countries such as the UK, France, Russia, and Italy, where the number of unintentional non-native introductions is highest in Europe [2]. The wels catfish has been extremely successful in expanding its range and now inhabits large rivers, lakes, backwaters, irrigated channels, ponds, and brackish waters. Though it is known to feed on a broad range of food items such as fish, amphibians, mammals, and birds, the real ecological effect of this species is still debated and its potential impact on native fish communities is far from being completely understood [3,4]. In fact, while for some authors the wels catfish is reported to exert a deep impact on native species [5], for others it is an opportunistic forager with a relatively low predatory pressure on zooplanktivorous fish $[3,4]$. Due to its piscivorous diet, S. glanis is assumed to represent a potential risk to autochthonous species and ecosystems [6]. In this view, according to some authors $[7,8]$, a confirmed predation on this species would greatly contribute to sustaining the ecological balance and the biotic integrity of the riverine ecosystems.

To evaluate and then quantify the predatory impact of Lutra lutra on S. glanis, we analyzed otter stools from the Ticino River (Northern Italy) considering that a dedicated campaign, conducted along this river to investigate the diet of a recently reintroduced otter population, reported the predation by this top predator on many fish species, S. glanis included [9]. Indeed, numerous efforts have been performed by the Ticino River Park 
Authorities to prevent the diffusion of S. glanis, but no significant results have been obtained, so a documented predation on this species was more than welcome and viewed with positive impacts on the native biota. Unfortunately, no mathematical equations tailored on S. glanis to back-calculate the original fish size have been available. Data from the many papers dealing with the feeding habits of otters showed that L. lutra prey on a wide range of fish from $<5$ up to $90 \mathrm{~cm}$ in length [10,11]; this leads to a great variety of fish bone remains in spraints, with consequent difficulties for the identification of species, also considering the lack of keys for the recently established exotic ones. Moreover, considering that L. lutra is highly flexible in fish predation [12] and that, according to Kruuk et al. [11] and Copp and Roche [13], its diet normally reflects the most abundant preys available, the finding of $S$. glanis remains in otter stools was not surprising; nevertheless, a detailed evaluation of wels catfish contribution in L. lutra diet is still lacking. To this end we analyzed otter stools focusing on the morphological features of fish remains as deduced by microscopic analyses, looking for those characteristics distinctive for S. glanis and to be used for its size determination. The specific aims of the present work are (i) the identification of bone characteristics for wels catfish detection in stools, (ii) the development of predictive equations for back-calculating the size of the preyed S. glanis, and (iii) the evaluation of the efficiency of otter predation on this invasive and still spreading species.

\section{Materials and Methods}

\subsection{Laboratory Collection of S. glanis}

Twenty-seven S. glanis samples with weights ranging from 10 to $323 \mathrm{~g}$ were taken by selective electrofishing during a containment program in the lower part of the Ticino River. Electrofishing was performed from a boat using an EL63 II GI device, 5000 Watt, 350/600 V max., generated by a portable Honda 4-stroke petrol engine GX270 (Scubla S.r.l., Remanzacco, Udine, Italy). In the laboratory, each sample was labeled with an identification code and morphometrically characterized according to [14] (Figure S1A). Eleven morphometric determinations were recorded for all specimens, and these data are available in the Supplementary Materials associated with the online version of the paper (see Table S1). All samples were then manually cleaned by removing their visceral parts, wrapped in aluminum foil, and cooked in an oven for $2-3 \mathrm{~h}$ at $150^{\circ} \mathrm{C}$. Subsequently, after a first gross manual cleaning (Figure S1B), the organic parts bound to the skeleton were removed by larvae of Hermetia sp. (Diptera, Stratiomyidae) according to Rojo [15]. Once cleaned, samples were taken separately for skeleton reconstruction and maintained in the laboratory as a reference material.

\subsection{Bone Measurements for Back-Calculations}

In the otter spraints collected along the Ticino River and analyzed by Smiroldo et al. [9], caudal vertebrae and a pharyngeal element have been reported as the most recognizable and recovered items for S. glanis. For comparative purposes, the same elements were compared with those coming from an osteological collection comprising fishes from the River Ticino. Secondly, for developing a quantitative tool for back-calculating the S. glanis size from the dimension of its caudal vertebrae, five $S$. glanis specimens, with weights ranging from 10 to $292 \mathrm{~g}$, were selected from the $S$. glanis collection. Detailed morphometric measurements (see Table S1) were taken from all the caudal vertebrae of these specimens: Each vertebra was photographed under a stereomicroscope, and the length as well as the mean diameter of each vertebra were measured on digital images using the free image processing software ImageJ [16]. The length of each vertebra was calculated as the distance between the two transverse planes delimiting the vertebral body, and its diameter was calculated as the mean value of the two perpendicular diameters passing through the center of the vertebra (Figure S1C,D).

Additionally, as a pharyngeal element was also recognized in the stools analyzed by Smiroldo et al. [9], the length and the width of this item was measured from all samples of our laboratory collection. Data from caudal vertebrae and pharyngeal elements were used 
to extrapolate mathematical relationships between bone size and fish weight, to be used for back-calculation.

\subsection{Ethical Statement}

S. glanis specimens analyzed in this work came from containment campaigns on the Ticino River performed in the Action C7 (Active defense of Acipenser naccarii spawning sites) of the "Ticino Biosource" LIFE project (LIFE15 NAT/IT/0000989, http:/ / ticinobiosource.it/ accessed on 12 April 2021). They were killed according to the ethical statement of the project and according to the DGR n.8/6308, 21/12/2007 of the Lombardy Region: "Management of Acipenser naccarii, of reproductive sites and of fishing", approved to guarantee the long-term survival of the species.

Bones from other fish species used for comparative analyses, if listed in the IUCN Red List of threatened species, came from laboratory or museum collections.

\subsection{Statistical Analyses}

Regression analyses between the bone size and fish weight were performed using a curve estimation mode (e.g., linear, exponential, quadratic, cubic, logarithmic, and polynomial). Regression models were tested for significance $(p<0.05)$, and the best fitting was chosen as the final model. A univariate general linear model (GLM) was used to test significant differences among the $\mathrm{K}$-index values in relation to the k-groups and the fish to which each vertebra belongs. K-index values were taken as dependent variables and k-groups and fish as factors after checking the normal distribution of K-index values (Kolmogorov-Smirnov test: $\mathrm{z}=0.67 ; n=244 ; p=0.76$ ). All statistical analyses were performed by the program SPSS v. 15.0.

\section{Results}

\subsection{S. glanis Identification by Pharyngeal Element}

Following Smiroldo et al. [9], who reported a pharyngeal element and the caudal vertebrae as diagnostic items for $S$. glanis identification, we microscopically analyzed the skeleton of 27 differently sized specimens from our laboratory collection. The pharyngeal elements from specimens prepared in the laboratory showed many little cone-shaped teeth onto their outer surface; these teeth were completely lacking in samples found in stools likely because of the transit through the otter's digestive system. This pharyngeal element was completely lacking in the skeletons of all the other considered fish species, except for the two catfish species. The comparison of these elements in S. glanis and I. punctatus is shown in Figure 1 (on the left and right, respectively, in each photograph).

Dental plates of both species showed some similarities but also some differences. The general morphology was quite similar: the shape looked like a spongy bean with the outer surface provided with a great number of small alveoli (Figure 1A). The inner face was characterized by an asymmetric supporting main structure and by few minor branch-like formations reaching the lateral edge of the plate (Figure 1B). Despite the similar general structure, the dental plate from S. glanis differed, e.g., from that of I. punctatus, by several features: the shape was more oval in S. glanis, the dental alveoli were thicker and smaller in I. punctatus than in S. glanis, and the bone plate opposite the toothed surface was divided into two lobes in I. punctatus, while it was polymorphous in S. glanis. Species identification is quite simple, but it requires a direct comparison of unknown samples with those in the laboratory collection. To our knowledge, no previous relationships for the back-calculation of the original fish size were proposed for these elements in the literature, and, although they are less frequent and more difficult to recognize than vertebrae, they represent useful tools for species identification and size back-calculation, which can be subsequently used in the diet determination of piscivorous predators. Since in fish the pharyngeal element was present in pairs, and the differences between pairs in our laboratory collection were negligible (the mean coefficients of variation between pairs were $0.97 \%$ and $2.0 \%$ for the length and width, respectively), we measured the length and width of both from all the 
specimens of the laboratory collection and we considered their mean values (Table S2). The two dimensions were both related to the known fish weight (polynomial regressions: $\left.\mathrm{R}^{2}>0.967 ; n=27 ; p<0.001\right)$, but the best fit was obtained with the length of the pharyngeal element $\left(R^{2}=0.989\right)$ described by the equation: $y=9.906 x^{2}-47.617 x+61.174$ (Figure 2).
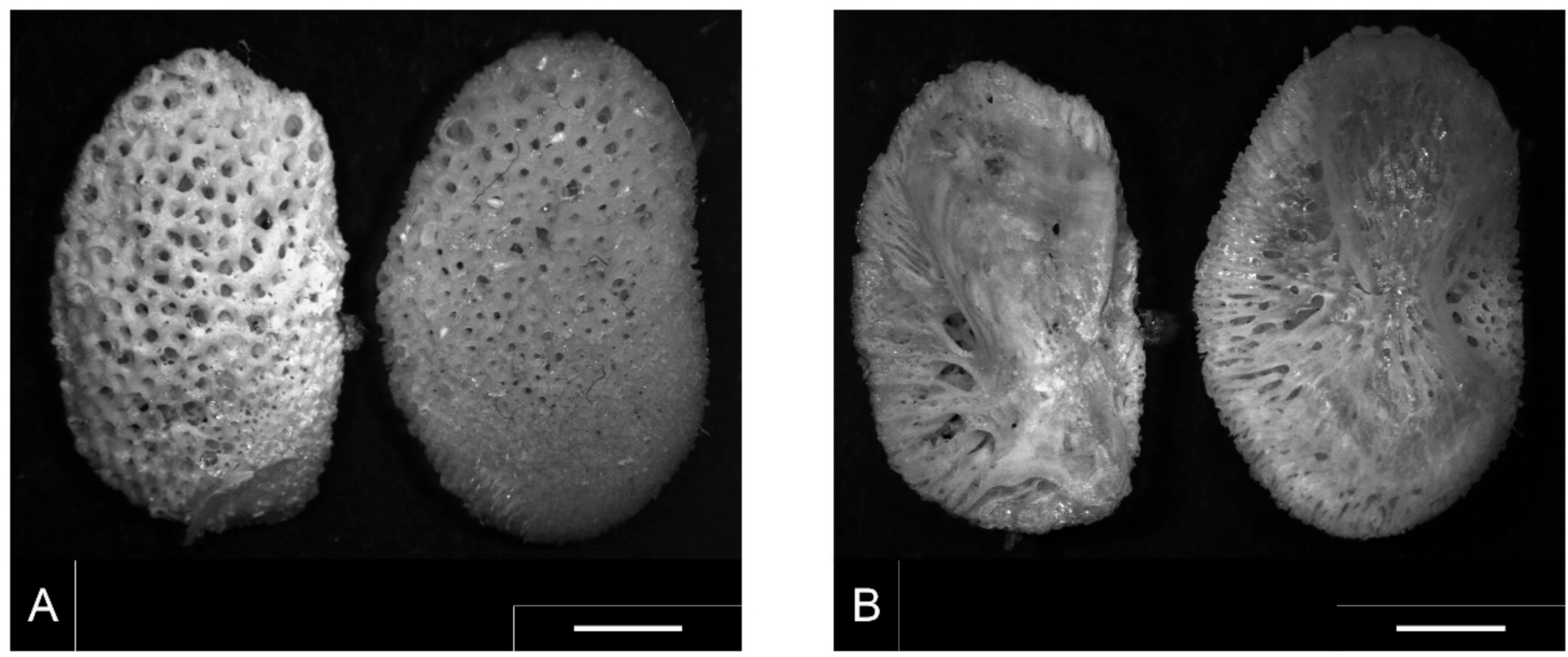

Figure 1. Comparison between the pharyngeal element of S. glanis (on the left in each photograph) and I. punctatus (on the right in each photograph). (A) = dorsal view; (B) ventral view. Bar $=2 \mathrm{~mm}$.

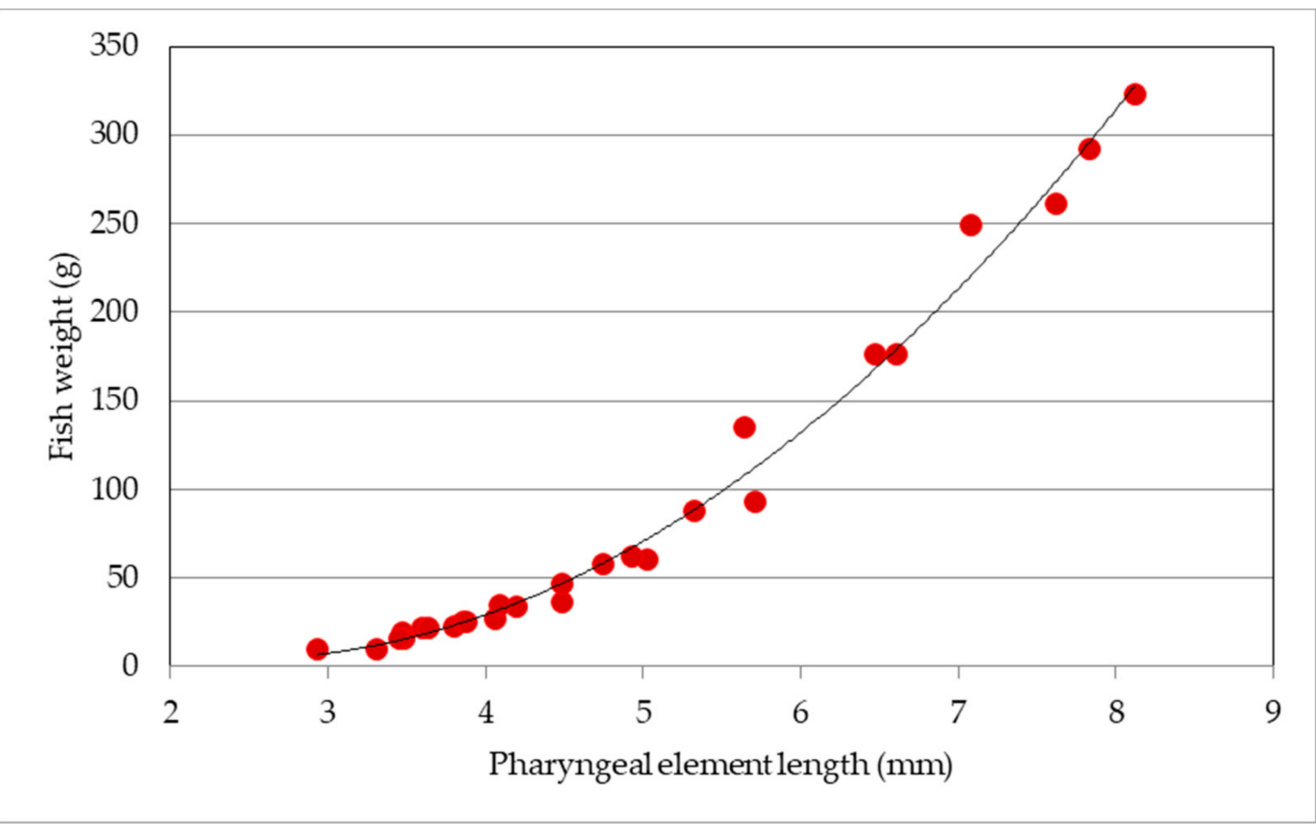

Figure 2. Relationship between the length of the pharyngeal element and fish weight $\left(y=9.906 x^{2}-\right.$ $\left.47.617 x+61.174 ; R^{2}=0.989\right)$.

\subsection{S. glanis Identification by Vertebra}

The second diagnostic element, also the most frequently recorded in stools, was represented by caudal vertebrae, in particular by the vertebral body, which, being well resistant to mechanical stress, was suitable not only for species identification but also for back-calculation of the original fish size. Vertebral processes are known to be useful tools for species identification [17], but they were not used here, as they represented weak structures that might be deeply damaged during the mastication and feeding processes, as 
observed in the otter stools. However, we found that the typical alveolar structure with a large hourglass rib of the vertebral body of $S$. glanis was a diagnostic element for species identification (Figure 3).

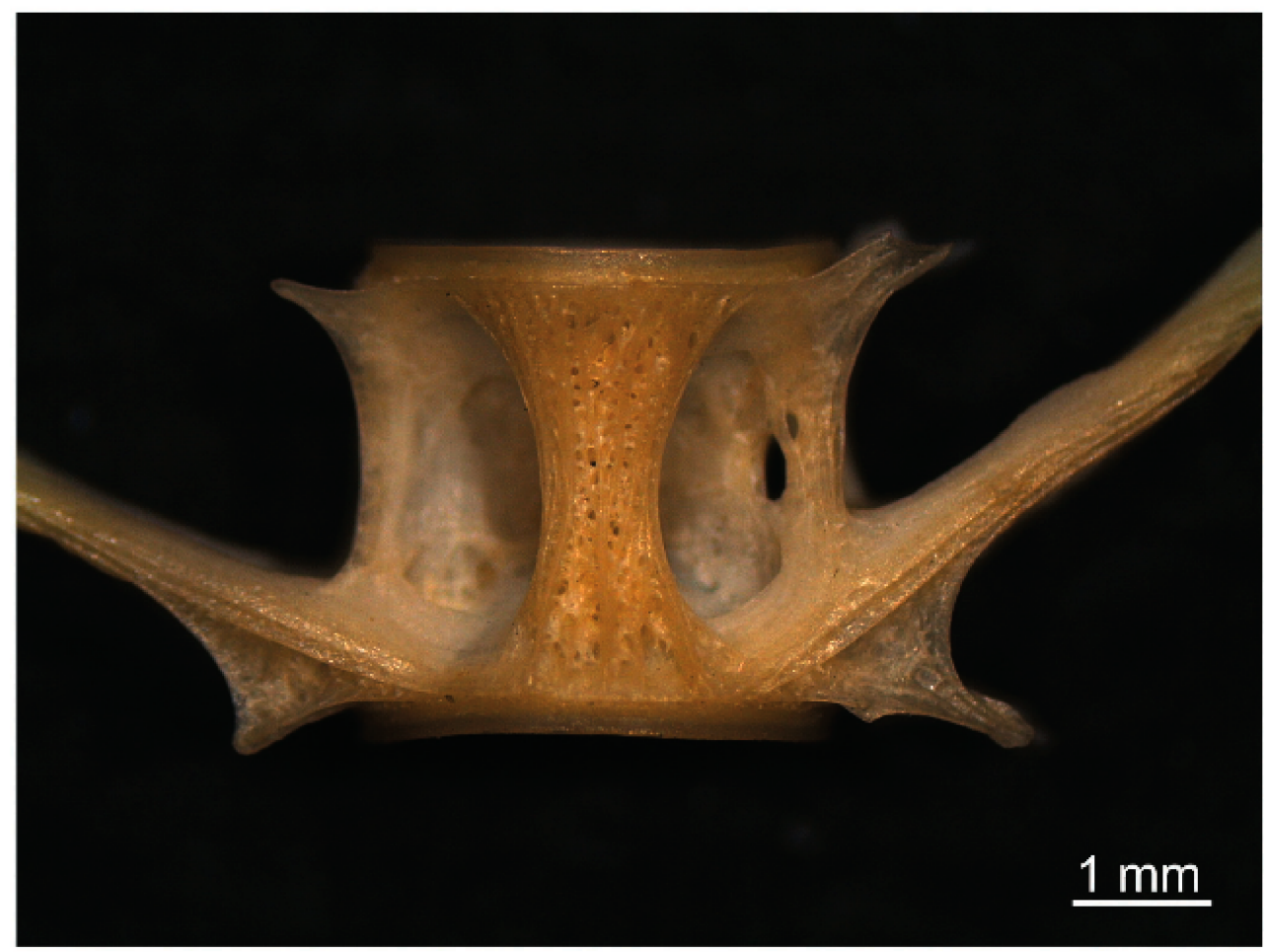

Figure 3. Detail of the vertebral body from a caudal vertebra of S. glanis.

Figure 4 shows the morphology of the caudal vertebrae of the species living in the Ticino River and coming from our laboratory collection.

Table 1 reports an updated list of the Ticino River fish, based on recent samplings (2019) carried out for the LIFE project "Ticino BioSource" (LIFE15 NAT/IT/000989).

Based on the morphology of the vertebral body, some species were very different, such as Anguilla anguilla, which had an evident enlargement of the spine base (Figure 4(1)), or Aspius aspius, which had two hourglass ribs (Figure 4(5)); other species, such as trout, which had a spongy honeycomb aspect of the wall of the vertebral body but no ribs (Figure 4(30-31)), or Ictalurus punctatus and I. melas, which are phylogenetically close to S. glanis, showed similar hourglass reinforcements but without the same alveolar structure found in S. glanis (Figure 4(33-35)). Vertebral processes were also significantly different and should be considered as well, but they were not used here, as they represented weak structures that might be deeply damaged during the mastication and feeding processes as reported before. The vertebral body, being more resistant to mechanical stress, was considered suitable both for species identification and for the back-calculation of the fish size. 

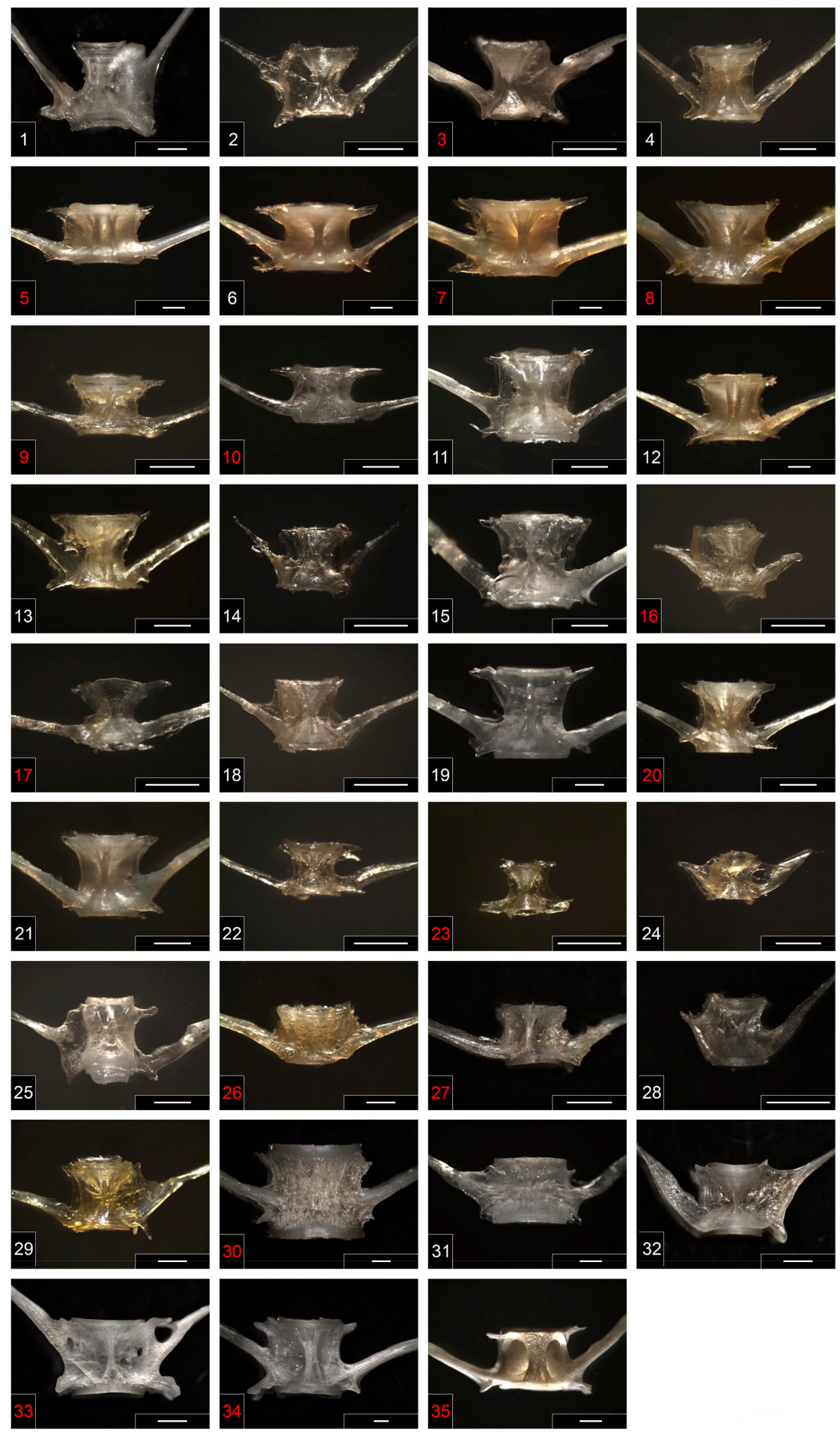

Figure 4. Comparative photographs of the vertebral body from most of the fish species living in the Ticino River. White number $=$ Autochthonous species; red number $=$ Allochthonous species. Bar $=1 \mathrm{~mm}$. 1 = Anguilla anguilla; 2 = Cobitis taenia $; 3=$ Misgurnus anguillicaudatus; $4=$ Alburnus alburnus; $5=$ Aspius aspius; 6 = Barbus plebejus; 7 = Blicca bioerkna; 8 = Carassius carassius; 9 = Ctenopharyngodon idella; 10 = Cyprinus carpio; 11 = Gobio gobio; 12 = Leuciscus cephalus; 13 = Leuciscus souffia; 14 = Phoxinus phoxinus; 15 = Protochondrostoma genei; 16 = Pseudorasbora parva; 17 = Rhodeus sericeus; $18=$ Rutilus erythrophtalmus; $19=$ Rutilus pigus; $20=$ Rutilus rutilus; $21=$ Scardinus erythrophtalmus; 22 = Tinca tinca; 23 = Gambusia holbrooki; 24 = Gasterosteus aculeatus; 25 = Salaria fluviatilis; 26 = Lepomis gibbosus; 27 = Micropterus salmoides; 28 = Knipowitschia punctatissima; 29 = Padogobius martensii; 30 = Perca fluviatilis; 31 = Salmo (trutta) marmoratus; 32 = Cottus gobio; 33 = Ictalurus melas; 34 = Ictalurus punctatus; 35 = Silurus glanis . 
Table 1. List of autochthonous (black) and allochthonous (red) species living in the Ticino River, IUCN classification, and abundance score $(\mathrm{Ab}$.$) : 1$ = rare; 2 = present; 3 = frequent; 4 = abundant; 5 =dominant as in Moyle and Nichols [18]. Species names shaded in gray are shown in Figure 5.

\begin{tabular}{|c|c|c|c|c|}
\hline Order & Family & Species & IUCN Red List & Ab. \\
\hline \multirow{27}{*}{$\begin{array}{c}\text { Acipenseriformes } \\
\text { Anguilliformes } \\
\text { Cypriniformes }\end{array}$} & \multirow{5}{*}{$\begin{array}{l}\text { Acipenseridae } \\
\text { Anguillidae } \\
\text { Cobitidae }\end{array}$} & Acipenser naccarii ${ }^{\dagger}$ & VU & 1 \\
\hline & & Anguilla anguilla & CR & 2 \\
\hline & & Cobitis taenia & LC & 3 \\
\hline & & Misgurnus anguillicaudatus & - & 3 \\
\hline & & Sabanejewia larvata & $\mathrm{LC}$ & 1 \\
\hline & \multirow[t]{22}{*}{ Cyprinidae } & Abramis brama & - & 1 \\
\hline & & Alburnus alburnus & DD & 4 \\
\hline & & Aspius aspius & - & 1 \\
\hline & & Barbus caninus & EN & 2 \\
\hline & & Barbus plebejus & LC & 4 \\
\hline & & Blicca bjoerkna & - & 3 \\
\hline & & Carassius carassius & - & 3 \\
\hline & & Chondrostoma soetta $^{\dagger}$ & EN & 1 \\
\hline & & Ctenopharyngodon idella & - & 1 \\
\hline & & Cyprinus carpio & - & 2 \\
\hline & & Gobio gobio & $\mathrm{LC}$ & 4 \\
\hline & & Leuciscus cephalus & $\mathrm{LC}$ & 5 \\
\hline & & Leuciscus souffia & $\mathrm{LC}$ & 4 \\
\hline & & Phoxinus phoxinus & $\mathrm{LC}$ & 3 \\
\hline & & Protochondrostoma genei & $\mathrm{LC}$ & 1 \\
\hline & & Pseudorasbora parva & - & 4 \\
\hline & & Rhodeus sericeus & - & 5 \\
\hline & & Rutilus erythrophthalmus & $\mathrm{LC}$ & 3 \\
\hline & & Rutilus pigus & DD & 2 \\
\hline & & Rutilus rutilus & - & 5 \\
\hline & & Scardinus erythrophtalmus & $\mathrm{LC}$ & 2 \\
\hline & & Tinca tinca & $\mathrm{LC}$ & 2 \\
\hline Cyprinodontiformes & Poecilidae & Gambusia holbrooki & - & 2 \\
\hline Esociformes & Esociformi & Esox lucius $^{\dagger}$ & $\mathrm{LC}$ & 2 \\
\hline Gadiformes & Lotidae & Lota lota & $\mathrm{LC}$ & 1 \\
\hline Gasterosteiformes & Gasterosteidae & Gasterosteus aculeatus & $\mathrm{LC}$ & 1 \\
\hline \multirow[t]{7}{*}{ Perciformes } & Blennidae & Salaria fluviatilis & $\mathrm{LC}$ & 2 \\
\hline & \multirow[t]{2}{*}{ Centrarchidae } & Lepomis gibbosus & - & 3 \\
\hline & & Micropterus salmoides & - & 3 \\
\hline & \multirow[t]{2}{*}{ Gobidae } & Knipowitschia punctatissima & NT & 2 \\
\hline & & Padogobius martensii & $\mathrm{LC}$ & 3 \\
\hline & \multirow[t]{2}{*}{ Percidae } & Perca fluviatilis & $\mathrm{LC}$ & 2 \\
\hline & & Stizostedion lucioperca & - & 2 \\
\hline \multirow{4}{*}{$\begin{array}{l}\text { Petromyzontiformes } \\
\text { Salmoniformes }\end{array}$} & \multirow{4}{*}{$\begin{array}{l}\text { Petromyzontidae } \\
\text { Salmonidae }\end{array}$} & Lethenteron zanandreai & $\mathrm{LC}$ & 1 \\
\hline & & Oncorhynchus mykiss & - & 2 \\
\hline & & Salmo (trutta) marmoratus ${ }^{\dagger}$ & $\mathrm{LC}$ & 1 \\
\hline & & Thymallus thymallus & LC & 1 \\
\hline & Cottidae & Cottus gobio & $\mathrm{LC}$ & 1 \\
\hline \multirow{3}{*}{ Siluriformes } & Ictaluridae & Ictalurus melas & - & 1 \\
\hline & & Ictalurus punctatus & - & 1 \\
\hline & Siluridae & Silurus glanis $\ddagger$ & - & 4 \\
\hline
\end{tabular}

${ }^{\dagger}=$ Species with active Conservation Program. ${ }^{\ddagger}=$ Species with active Containing Campaign.

Unfortunately, differently from the pharyngeal elements, vertebrae presented some problems in the back-calculation procedures: in fact, fish of the same size could have vertebrae of very different sizes, depending on the relative position along the column. As discussed later, vertebral morphology varies along the vertebral column, and bone remains in otter stools are usually limited in number, sometimes damaged, such that the sole morphological approach may not be applicable for identifying the position along the column. For this reason, a quantitative tool able to identify the position of each vertebra 
along the column would be very useful in this kind of analysis. We thus selected from our collection five $S$. glanis samples with a total weight ranging between 10 and $292 \mathrm{~g}$ (Table S1), and we measured the length and the mean diameter of all caudal vertebrae from each specimen to find and then propose an index that allows one to identify the vertebral position along the column. We found that the ratio between the length and the mean diameter of the vertebral body was a good index for our purposes because it increased along the vertebral column in the cephalo-caudal direction between 0.7 and 1.4 for all the considered fish, independently from their size. We defined this as the K-index (Figure 5).

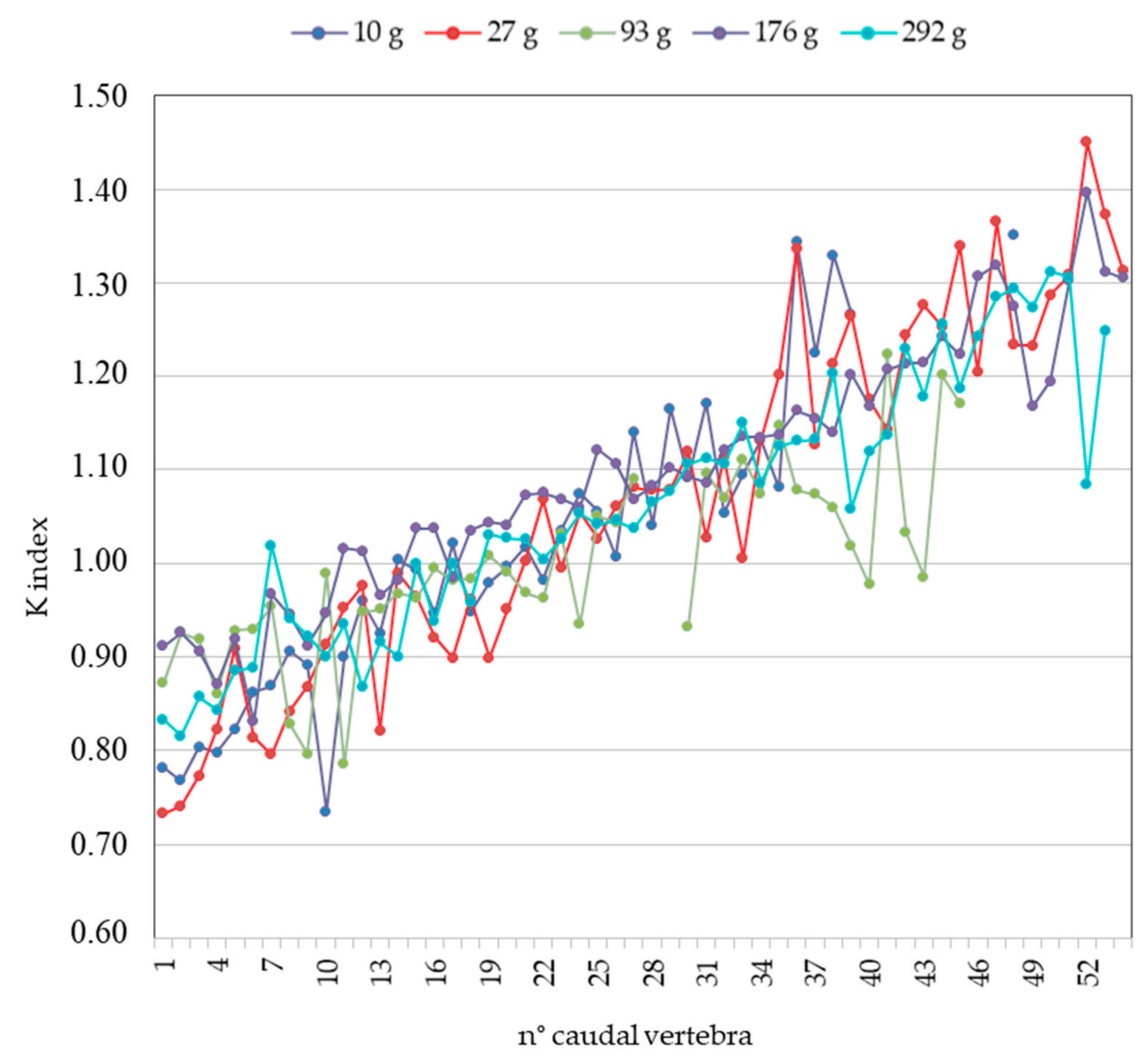

Figure 5. Ratio between length and mean vertebral diameter (K-index) along the column in the cephalo-caudal direction in the considered samples.

The increase in the K-index along the column depended on the fact that the mean diameter (denominator) decreased more rapidly than the vertebral length (numerator). Considering the numerical range of the K-index $(0.7-1.4)$, for practical reasons, we divided it into five biometric groups: 0.7 to $0.9 ;>0.9$ to $1.0 ;>1.0$ to $1.1 ;>1.1$ to $1.2 ;>1.2$ to 1.4 . The first and the last group presented an interval higher than the others because, at the beginning and at the end of the vertebral column, the K-index values varied greatly for a lower number of vertebrae, more than in the central portion of the column. The K-index values of each vertebra of the five fishes were significantly related to the five $\mathrm{K}$ groups (GLM: $\left.\mathrm{F}_{4 ; 219}=521 ; p<0.001\right)$-not to the fish to which they belong (GLM: $\mathrm{F}_{4 ; 219}=0.70$; $p=0.59$ ) - and therefore to the fish size. Even the interaction between groups and fish was not significant (GLM: $\left.F_{16 ; 219}=1.29 ; p=0.21\right)$, meaning that there were no differences in the $\mathrm{K}$-index values of the vertebrae among the five groups depending on fish size.

The number of vertebrae falling in each group ranged between 7 and 13, the mean value of the K-index of the vertebrae falling in the same group was very similar to the central value of the interval, and the $95 \%$ confidence interval of each group was very near to the mean value (Table 2). 
Table 2. Central and mean values of the K-index in the five $\mathrm{K}$ groups.

\begin{tabular}{cccc}
\hline K Group & Central Value & Mean & $\mathbf{9 5 \%}$ CI \\
\hline $0.7-0.9$ & 0.8 & 0.84 & $0.821-0.852$ \\
$>0.9-1.0$ & 0.95 & 0.95 & $0.942-0.962$ \\
$>1.0-1.1$ & 1.05 & 1.05 & $1.041-1.060$ \\
$>1.1-1.2$ & 1.15 & 1.14 & $1.127-1.156$ \\
$>1.2-1.4$ & 1.3 & 1.27 & $1.253-1.283$ \\
\hline
\end{tabular}

Once the method to assign each vertebra to a specific group was identified, we were able to define five quantitative relationships for calculating the fish weight from the vertebral size. The mean diameter was chosen as the "best vertebral size parameter" because it showed a greater variability range along the vertebral column than the vertebral length. In fact, the lower interval of vertebral length would have generated a lower precision in fish mass determination. Therefore, the mean diameter of the vertebrae belonging to each group was related to the known fish weight, obtaining five regression equations shown in Figure 6 and reported in Table 3.
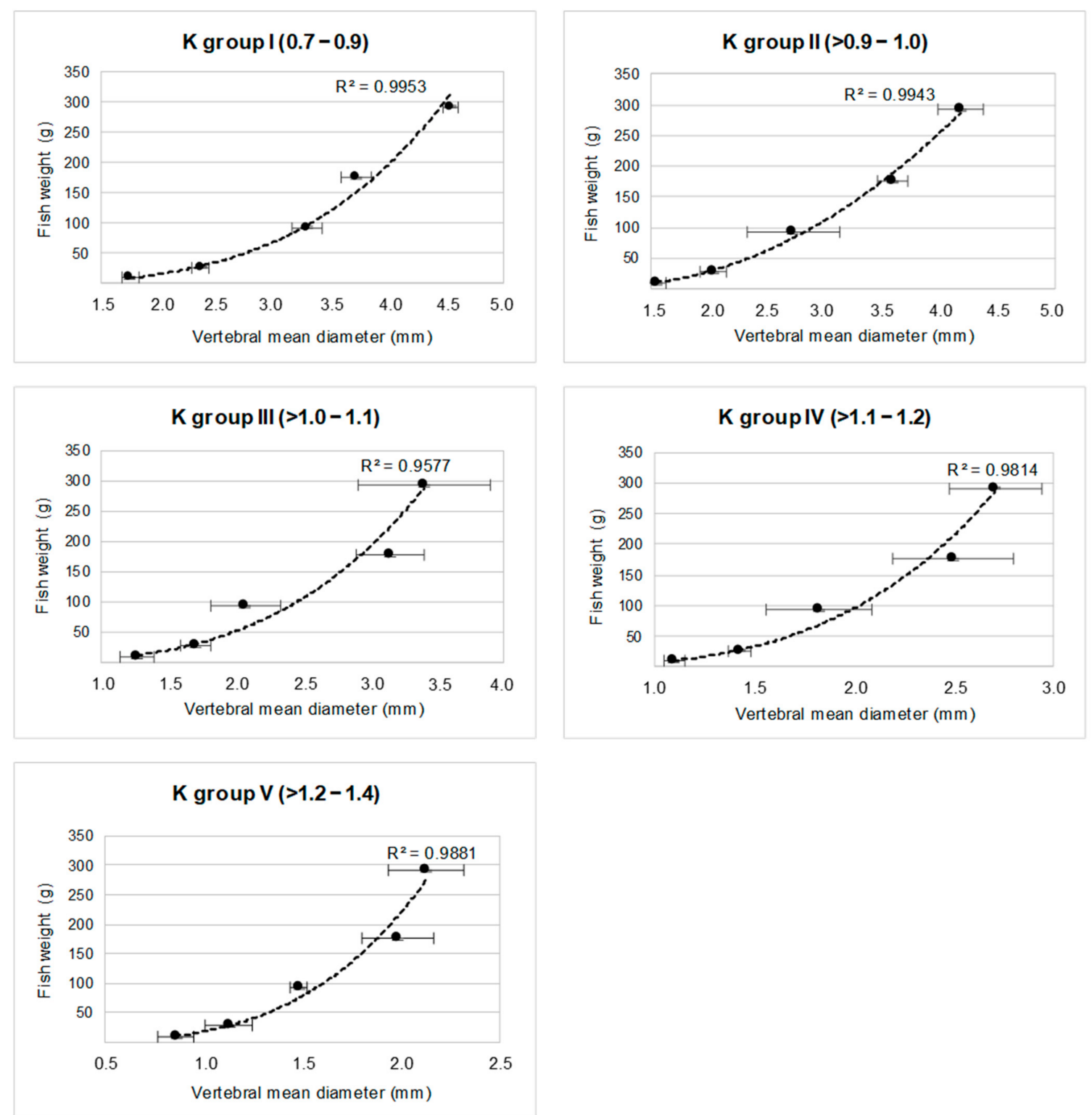

Figure 6. Regressions between the mean vertebral diameter and fish weight in the five selected K groups. 
Table 3. Regression equations of the five K groups.

\begin{tabular}{cccc}
\hline K Group & Equation & $\mathbf{R}^{\mathbf{2}}$ & $p$ \\
\hline I & $\mathrm{y}=1.254 \mathrm{x}^{3.6517}$ & 0.99 & $<0.001$ \\
II & $\mathrm{y}=30.359 \mathrm{x}^{2}-69.158 \mathrm{x}+45.018$ & 0.99 & $<0.001$ \\
III & $\mathrm{y}=5.434 \mathrm{x}^{3.2412}$ & 0.96 & $<0.001$ \\
IV & $\mathrm{y}=7.842 \mathrm{x}^{3.6157}$ & 0.98 & $<0.001$ \\
V & $\mathrm{y}=18.056 \mathrm{x}^{3.6038}$ & 0.99 & $<0.001$ \\
\hline
\end{tabular}

In this way, a vertebra found in otter feces can be assigned by its $\mathrm{K}$-index to a " $\mathrm{K}$ "group, and the weight of a predated individual, as it was before ingestion, can be deduced through the relationship between the mean diameter and the fish mass of that group.

\subsection{Model Validation}

To verify this approach and to assess the variability derived by the back-calculation procedure, a model validation was performed with an independent set of data. For this purpose, three new $S$. glanis specimens were selected having low, medium, and high weight to back-calculate their known weights starting from their vertebrae. Table 4 reported the known fish mass of the three selected fish and the mean back-calculated fish mass for each k-group and for each fish, with the mean coefficient of variation of the calculated masses derived by all vertebrae divided in the five k-groups by means of their K-indexes.

Table 4. Fresh and back-calculated weights $( \pm \mathrm{SD})$ of three $S$. glanis samples from our laboratory collection. Back-calculated weights were obtained from each vertebra of each $\mathrm{K}$ group.

\begin{tabular}{cccc}
\hline & \multicolumn{3}{c}{ S. glanis Weight (g) } \\
\hline Fresh weight & 20 & 60 & 323 \\
Calculated Group I & $18.4 \pm 1.7$ & $54.9 \pm 1.2$ & $366 \pm 26$ \\
Calculated Group II & $22.2 \pm 3.5$ & $69.8 \pm 8.6$ & $309 \pm 35$ \\
Calculated Group III & $24.0 \pm 4.3$ & $70.8 \pm 13.8$ & $355 \pm 84$ \\
Calculated Group IV & $19.4 \pm 5.0$ & $71.2 \pm 11.5$ & $371 \pm 126$ \\
Calculated Group V & $18.6 \pm 6.3$ & $67.1 \pm 26.8$ & $338 \pm 98$ \\
Mean weight & $\mathbf{2 0 . 4} \pm \mathbf{4 . 9}$ & $\mathbf{6 7 . 5} \pm \mathbf{1 7 . 7}$ & $\mathbf{3 4 7} \pm \mathbf{8 8}$ \\
Coefficient of variation (\%) & 24 & 26 & 25 \\
\hline
\end{tabular}

Calculated fish masses were very similar within the five k-groups (mean coefficient of variation ranging between $2.2 \%$ and $34 \%$ ) and among groups (mean coefficient of variation ranging between $7.2 \%$ and $12 \%$ ). The overall mean coefficient of variation of the calculated fish masses coming from all the vertebrae of all fish was $25 \%$. In addition, mean calculated fish masses were very similar to the known fish mass values (mean percentage difference between calculated and known fish mass was $7.6 \%$ ).

\subsection{Back-Calculation of the S. glanis Size in Otter's Stools}

In the case of predictions of unknown fish masses from vertebral remains found in spraints, we can suppose that, when several vertebrae found in the same stool gave the same fish weight, we assumed that they belonged to the same specimen, whereas, when different vertebrae provided different fish weights, we assigned them to different individuals. For defining the weight similarities between two back-calculated fish masses, the mean variability derived from the proposed back-calculation procedure was considered. Therefore, two back-calculated weights belonging to different fish were considered if they differed by more than $30 \%$ (percentage difference between the two back-calculated weights).

In this work, 13 bony components from 8 different stools were analyzed (12 caudal vertebrae and 1 pharyngeal element), and the obtained back-calculated fish masses are reported in Table 5 . 
Table 5. Back-estimation of S. glanis weights from bone remain analysis.

\begin{tabular}{|c|c|c|c|c|c|c|c|}
\hline Stool ID & $\begin{array}{l}\text { Sampling Date } \\
\text { (DDMMYYYY) }\end{array}$ & $\begin{array}{c}\text { Bone } \\
\text { Remain }\end{array}$ & $\begin{array}{c}\text { Mean Diameter } \\
(\mathrm{mm})\end{array}$ & Height (mm) & K Index & $\begin{array}{c}\text { K } \\
\text { Group }\end{array}$ & $\begin{array}{r}\text { Estimated } \\
\text { Weight (g) }\end{array}$ \\
\hline Ticino 25 & $22 / 10 / 2016$ & $\mathrm{c} \mathrm{V}$ & 4.31 & 3.43 & 0.8 & I & 260 \\
\hline Ticino 26 & $22 / 10 / 2016$ & $\mathrm{c} \mathrm{V}$ & 0.99 & 1.03 & 1.04 & III & 5 \\
\hline Ticino 26 & $22 / 10 / 2016$ & $\mathrm{c} \mathrm{V}$ & 1.98 & 1.69 & 0.86 & I & 15 \\
\hline Ticino 27 & $10 / 09 / 2016$ & $\mathrm{c} \mathrm{V}$ & 3.25 & 3.6 & 1.11 & IV & 556 \\
\hline Ticino 28 & $10 / 09 / 2016$ & $\mathrm{c} \mathrm{v}$ & 3.22 & 3.25 & 1.01 & III & 240 \\
\hline Ticino 57 & $28 / 01 / 2017$ & $\mathrm{cv}$ & 2.58 & 2.87 & 1.11 & IV & 241 \\
\hline Ticino 58 & $28 / 01 / 2017$ & $\mathrm{c} \mathrm{v}$ & 0.86 & 1.19 & 1.38 & $\mathrm{~V}$ & 10 \\
\hline Ticino 58 & $28 / 01 / 2017$ & $\mathrm{c} \mathrm{V}$ & 0.73 & 1.13 & 1.55 & $\mathrm{~V}$ & 9 \\
\hline Ticino 61 & $28 / 01 / 2017$ & $\mathrm{c} \mathrm{v}$ & 2.26 & 1.7 & 0.75 & I & 25 \\
\hline Ticino 61 & $28 / 01 / 2017$ & $\mathrm{cv}$ & 1.4 & 1.44 & 1.03 & III & 16 \\
\hline Ticino 61 & $28 / 01 / 2017$ & $\mathrm{c} \mathrm{v}$ & 1.54 & 1.58 & 1.03 & III & 22 \\
\hline Ticino 95 & $18 / 03 / 2017$ & $\mathrm{c} \mathrm{v}$ & 1.8 & 2.2 & 1.22 & $\mathrm{~V}$ & 150 \\
\hline Ticino 58 & $28 / 01 / 2017$ & $\mathrm{pe}$ & & $2.75^{\mathrm{a}}$ & & & 5 \\
\hline
\end{tabular}

$\mathrm{c} \mathrm{v}=$ caudal vertebra. $\mathrm{p} \mathrm{e}=$ pharyngeal element. $^{\mathrm{a}}=$ length of the pharyngeal element $(\mathrm{mm})$.

According to our methodology, diagnostic elements in the same stool were attributed to the same individual if the resulting fish weights were similar (within a $30 \%$ difference). An example of two elements very likely belonging to the same fish are those whose estimated weights were 10 and $9 \mathrm{~g}$ in the sample Ticino 58 reported in Table 5. On the contrary, when estimated fish weight was very similar, but the diagnostic elements came from different stools, they were attributed to different individuals (e.g., the estimated fish weights of 240 and $241 \mathrm{~g}$ in Ticino 28 and Ticino 57, respectively, Table 5). A third possibility was the finding of diagnostic elements in the same stool, giving very different estimated weights (e.g., estimated weights of 5 and $15 \mathrm{~g}$ in Ticino 26, Table 5). In this case, two different specimens were considered. In total, 10 individuals in 8 stools were identified, and the mean weight of the preyed S. glanis was $150 \pm 179 \mathrm{~g}$, within a range of 5-556 g. Fish weight is an important parameter in evaluating an otter's diet, because it allows one to establish the relative contribution of the species in the overall diet, but for $S$. glanis population dynamics, the length and the age of the preyed fish should be considered as well. In the Ticino River, the S. glanis population was studied during containment campaigns, and the relationships between weight and length and between length and age were determined [19]. These relationships were as follows: fish weight $(\mathrm{g})$ in natural logarithm $=-11.279+2.897 *$ total length $(\mathrm{mm})$ in natural logarithm $\left(R^{2}=0.96\right)$, and total length $(\mathrm{mm})=1900.041 *(1-\exp (-0.098 *($ fish age $($ years $)+0.74)))\left(R^{2}=0.96\right)$, respectively. By these equations, the mean length of the preyed S. glanis was $224 \pm 129 \mathrm{~mm}$, with a range of $85-435 \mathrm{~mm}$ and the mean age of the preyed S. glanis was $0.64 \pm 0.72$ year, with a range between $0+$ and $2+$ years. Length distribution of preyed S. glanis specimens showed that the most preyed class was between 250 and $350 \mathrm{~mm}$ and about 1 year old.

\section{Discussion}

Due to the increasing diffusion of alien species, a deep knowledge of the interactions between native and non-native species is a crucial goal to be achieved for drawing future conservation strategies. In the Ticino River, S. glanis has been detected since 1994, initially as occasional species, but it was defined as abundant as early as 1998 [19]. The Ticino River's S. glanis population came from the Po River and since grew very quickly. In 2003, the Park authority promoted a containment campaign, as a conservation action for autochthonous species, in particular for the conservation of the critically endangered Acipenser naccarii, an endemism of the Po River basin [19]. Campaigns for S. glanis containment along the Ticino River are still ongoing, and in this context, the identification of $S$. glanis remains in otter stools in [9] represented an important finding. Unfortunately, no specific analyses were performed in that paper, and no indications of the number and the size of the preyed fish are yet available. For this reason, specific mathematical equations were developed 
to back-calculate the original fish size starting from S. glanis bone remains in feces. Two diagnostic elements (vertebrae and a pharyngeal bone) were selected. Otoliths, other elements often used in back-calculation procedures, were not considered here because they were not found. Indeed, otoliths are known to be subject to chemical degradation and possibly mechanical abrasion in the digestive tract of predators [20,21], making some species impossible to be recognized [22]. On the contrary, vertebrae and other bone remains were expected to be more resistant than otoliths and consequently more easily traceable in the feces of piscivore species [21]. For this reason, according to Feltham and Marquiss [23], Feltham [24], and Desse and Desse-Berset [25], they were proposed as suitable tools to estimate the minimum number of prey and to back-calculate their size.

Vertebrae have different characteristics useful in species determination, for example, the morphology of dorsal and ventral pre- and post-zygapophyses, the size and shape of neural and hemal spines, the sculpturing of the centrum, and the location and size of foramina [17,21]. Conroy et al. [26] suggested a key based on fish vertebrae considering 21 families, but they did not include S. glanis or other Siluriformes, nor did Hermsen and Maarseveen in the key that they suggested [27]. As already stated, we considered a typical alveolar structure with a large 'hourglass' rib of the vertebral body of S. glanis as a diagnostic element, since it was different from that of other fish species. Vertebral processes were not used here for species identification, as they represented weak structures that might be deeply damaged during the mastication and feeding processes as reported before.

In the literature, there are many equations for calculating fish size from vertebral length (e.g., equations from Thom [28] regarding trout). For S. glanis, a mathematical equation existed as well, but it was based only on the 13th thoracic vertebra [29]. As mentioned before, the main problem of using vertebrae in back-calculation is that, frequently, few recognizable vertebrae are found in feces, and since they can be very damaged, the determination of their relative position along the column may be uncertain. For this reason, the use of just one relationship for all vertebrae is not suitable. On the contrary, the proposed K-index was demonstrated (validation procedure) to be a quantitative tool for determining the position of each vertebra along the column and thus for back-calculating the fish mass of the prayed specimen with an acceptable accuracy (mean percentage difference between calculated and known fish mass was 7.6\%). An additional advantage of the K-index was the fact that it could be calculated on the same vertebral body used for species identification and fish mass back-calculation. Moreover, the K-index methodology avoids the need to provide a number of equations equal to the number of the vertebrae and, therefore, the need to identify, vertebra by vertebra, the exact position in the vertebral column, which requires that all vertebral structures (spines, lateral apophyses, and zygapophyses) are not damaged (a rarely occurring condition). On the contrary, the K-index requires only two simple parameters: the mean diameter and the vertebral length.

The second element used in the species determination and back-calculation of fish mass was an oval pharyngeal element. These elements are involved in the function of retaining food items from the water flux crossing gills [15]. In light of the high number of teeth covering the whole surface of these elements, they can also furnish additional food fragmentation prior to entering the digestive system. These structures were lacking in all other species from the Ticino River, except for the two catfish species. As reported in the Results section (Figure 1), the dental plate from S. glanis differed from that of I. punctatus in several features: the shape appeared bean-shaped in I. punctatus and more oval in $S$. glanis, the dental alveoli were thicker and smaller in I. punctatus than in S. glanis, and the bone plate opposite the teeth bearing surface was divided into two lobes in I. punctatus, while it was irregularly shaped in S. glanis. Although less frequent and more difficult to recognize than vertebrae, these pharyngeal elements represented additional tools for species identification to be used in the diet determination of piscivorous predators. To our knowledge, no previous relationships were proposed for these elements in the literature. 


\section{Conclusions}

The main conclusions of this work can be summarized as follows:

- The alveolar structure of the hourglass rib on the vertebral body of S. glanis is a diagnostic element for species identification, as are the shape and structure of the pharyngeal dental plate.

- The proposed K-index is able to identify the vertebral position along the column, independently from the fish size, and the set of predictive equations developed and validated in this work can establish the size of the preyed fish with a good level of accuracy.

- The back-calculation of the original size of preyed fish open new perspectives for more detailed studies on the diet of piscivorous predators as well as on control efficacy by the predation to prevent uncontrolled growth of allochthonous species.

- $\quad$ The proposed methodology applied to S. glanis remains in otter stools from the Ticino River revealed the predation of 10 specimens with weights ranging between 5 and $550 \mathrm{~g}$, lengths between 85 and $435 \mathrm{~mm}$, and ages between 0 and 2 years, with more frequent predation on specimens about 1 year old and $250-350 \mathrm{~mm}$ in length.

Supplementary Materials: The following are available online at https: / www.mdpi.com/article/ 10.3390/su13084322/s1, Figure S1: (A) Some of the S. glanis samples used for the morphometric characterization. (B) One S. glanis specimen during the cleaning procedure. (C,D) Measurements used for the K-index determination ( $\mathrm{C}=$ length; $\mathrm{D}=$ diameters). Table S1: Morphometric characterization of S. glanis samples. Table S2: Length and width of the pharyngeal elements from each S. glanis sample.

Author Contributions: Conceptualization, R.B. and P.T.; methodology, R.B. and P.T.; experimental work, R.B., A.M., and A.N.; data curation and statistical analyses, R.B. and P.T.; writing-original draft preparation, R.B. and P.T.; writing - review and editing, R.B. and P.T. All authors have read and agreed to the published version of the manuscript.

Funding: This research received no external funding.

Institutional Review Board Statement: This study did not involve live animals, as reported in Section 2.3 of the Material and Methods (Ethical Statement), all animals considered in this study came from museal collections or were killed in containment campaigns authorized by Lombardy Region (DGR n.8/6308, 21/12/2007).

Data Availability Statement: Original data used in this study are reported in tables in the manuscript or in the Supplementary Materials. Osteological collection of S. glanis specimens and of those of the other fish species cited in the manuscript are deposited in the Ecology laboratory of the Department of Environmental Science and Policy, Università degli Studi di Milano, 26, Via G. Celoria, I-20133 Milan, Italy. The collection is available on request to the corresponding author.

Acknowledgments: The authors are very grateful to Fondazione Fratelli Confalonieri (Milano, Italy) for granting a PhD fellowship on otter ecology, the Endangered Landscape Program (ELP) of the Cambridge Conservation Initiative (Cambridge, UK) for founding the project "Restoring the Ticino River Basin Landscape. One River-Many Systems-One Landscape", Cesare Puzzi, cofounder of Graia s.r.l. (Varano Borghi, Varese, Italy), for kindly providing S. glanis specimens from the Ticino River, Andrea Casoni from Graia s.r.l. and Giuseppe Meriggi from FIPSAS (Pavia, Italy) for kindly providing fish specimens from the Ticino River, and Elena Menegola, Università degli Studi di Milano, for her helpful advice.

Conflicts of Interest: The authors declare no conflict of interest.

\section{References}

1. Stone, R. The last of the leviathans. Science 2007, 316, 1684-1688. [CrossRef]

2. Copp, G.H.; Bianco, P.G.; Bogutskaya, N.G.; Eros, T.; Falka, I.; Ferreira, M.T.; Fox, M.G.; Freyhof, J.; Gozlan, R.E.; Grabowska, J.; et al. To be, or not to be, a non-native freshwater fish? J. Appl. Ichthyol. 2005, 21, 242-262. [CrossRef]

3. Hickley, P.; Chare, S. Fisheries for non-native species in England and Wales: Angling or the environment? Fish. Manag. Ecol. 2004, 11, 203-212. [CrossRef] 
4. Wysujack, K.; Mehner, T. Can feeding of European catfish prevent cyprinids from reaching a size refuge? Ecol. Freshw. Fish 2005, 14, 87-95. [CrossRef]

5. Valadou, B. Le Silure Glane (Silurus glanis, L.) en France. Évolution de son Aire de Répartition et Prédiction de son Extension; Conseil Supérieur de la Pêche: Fontenay-sous-Bois, France, 2007.

6. Copp, G.H.; Britton, R.J.; Cucherousset, J.; García-Berthou, E.; Kirk, R.; Peeler, E.; Stakenas, S. Voracious invader or benign feline? A review of the environmental biology of European catfish Silurus glanis in its native and introduced ranges. Fish Fish. 2009, 10, 252-282. [CrossRef]

7. Prenda, J.; Clavero, M.; Blanco-Garrido, F.; Menor, A.; Hermoso, V. Threats to the conservation of biotic integrity in Iberian fluvial ecosystems. Limnetica 2006, 25, 377-388.

8. Miranda, R.; Copp, G.H.; Williams, J.; Beyer, K.; Gozlan, R.E. Do Eurasian otters Lutra lutra (L.) in the Somerset Levels prey preferentially on non-native fish species? Fundam. Appl. Limnol. 2008, 266, 255-260. [CrossRef]

9. Smiroldo, G.; Balestrieri, A.; Pini, E.; Tremolada, P. Anthropogenically altered trophic webs: Alien catfish and microplastics in the diet of Eurasian otters. Mammal Res. 2019, 64, 165-174. [CrossRef]

10. Carss, D.N.; Kruuk, H.; Conroy, J.W.H. Predation on adult Atlantic salmon, Salmo salar L. by otters, Lutra lutra (L.) within the River Dee system, Aberdeenshire, Scotland. J. Fish Biol. 1990, 37, 935-944. [CrossRef]

11. Kruuk, H.; Carss, D.N.; Conroy, J.W.H.; Durbin, L. Otter Lutra lutra numbers and fish productivity in rivers of North East Scotland. Symp. Zool. Soc. Lond. 1993, 65, 9-13.

12. Weinberger, I.C.; Muff, S.; de Jongh, A.; Kranz, A.; Bontadina, F. Flexible habitat selection paves the way for a recovery of otter populations in the European Alps. Biol. Conserv. 2016, 199, 88-95. [CrossRef]

13. Copp, G.H.; Roche, K. Range and diet of Eurasian otters Lutra lutra (L.) in the catchment of the River Lee (south-east England) since re-introduction. Aquat. Conserv. Mar. Freshw. Ecosyst. 2003, 13, 65-76. [CrossRef]

14. Rutkayová, J.; Biskup, R.; Harant, R.; Šlechta, V.; Koščo, J. Ameiurus melas (black bullhead): Morphological characteristics of new introduced species and its comparison with Ameiurus nebulosus (brown bullhead). Rev. Fish Biol. Fish. 2013, 23, 51-68. [CrossRef]

15. Rojo, A. Osteological Atlas of the Brown Bullhead (Ameiurus nebulosus) from Nova Scotia Waters: A Morphological and Biometric Study; Curatorial Report Number 100; Nova Scotia Museum: Halifax, NS, Canada, 2013.

16. Schneider, C.A.; Rasband, W.S.; Eliceiri, K.W. NIH Image to ImageJ: 25 years of image analysis. Nat. Methods 2012, 9, 671-675. [CrossRef] [PubMed]

17. Desse, G.; Du Buit, M.-H. Diagnostic des Pièces Rachidiennes des Téléostéens et des Chondrichthyens. III Téléostéens d'eau Douce; Expansion Scientifique Française: Paris, France, 1971.

18. Moyle, P.; Nichols, R.D. Ecology of Some Native and Introduced Fishes of the Sierra Nevada Foothills in Central California. Copeia 1973, 3, 478-490. [CrossRef]

19. Puzzi, C.M.; Trasforini, S.; Casoni, A.; Bardazzi, M.A.; Bellani, A. Il siluro (Silurus glanis). Ecologia della Specie nel Fiume Ticino e Risultati Dell'azione di Contrasto alla Sua Espansione Svolta dal Parco Negli Anni 2001-2006; Consorzio del Parco Lombardo della Valle del Ticino; Pontevecchio di Magenta: Milan, Italy, 2007.

20. Pierce, G.J.; Boyle, P.R. A review of methods for diet analysis in piscivorous marine mammals. Oceanogr. Mar. Biol. Ann. Rev. 1991, 29, 409-486.

21. Pierce, G.J.; Boyle, P.R.; Watt, J.; Grisley, M. Recent advances in diet analysis of marine mammals. Symp. Zool. Soc. Lond. 1993, 66, 241-261.

22. Granadeiro, J.P.; Silva, M.A. The use of otoliths and vertebrae in the identification and size-estimation of fish in predator-prey studies. Cybium 2000, 24, 383-393.

23. Feltham, M.J.; Marquiss, M. The use of first vertebrae in separating, and estimating the size of trout (Salmo trutta) and salmon (Salmo salar) in bone remains. J. Zool. 1989, 219, 113-122. [CrossRef]

24. Feltham, M.J. The diet of red-breasted mergansers (Mergus serrator) during the smolt run in N.E. Scotland: The importance of salmon (Salmo salar) smolts and parr. J. Zool. 1990, 222, 285-292. [CrossRef]

25. Desse, J.; Desse-Berset, N. Archaeozoology of groupers (Epinephelinae) identification, osteometry and keys to interpretation. Archaeofauna 1996, 5, 121-127.

26. Conroy, J.W.H.; Watt, J.; Webb, J.B.; Jones, A. A Guide to the Identification of Prey Remains in Otter Spraints, 3rd ed.; The Mammal Society: London, UK, 2005.

27. Hermsen, J.; Maarseveen, A.V. A Diet Study of the Eurasian Otter (Lutra lutra) Based on Spraint Analysis; Niewold Wildlife Infocentre: Leeuwarden, The Netherlands, 2011.

28. Thom, T.J. The Ecology of Otters (Lutra lutra) on the Wansbeck and Blyth River Catchements in Northumberland; Durham E-Theses; Durham University: Durham, UK, 1990.

29. Hensel, K. Find of a capital wels catfish Silurus glanis (Actinopterygii: Siluridae) in excavations of a Roman military fort in Southern Slovakia. Biologia 2004, 15, 191-203. 